Acta Poetica $26(1-2)$

PRIMAVERA-OTOÑO

2005

\title{
Un baile perseguido del siglo XVIII, un son y un juego infantil del xx: algunos textos de la jeringonza en México
}

\author{
Mariana Masera
}

La jeringonza fue uno de los bailes más difundidos y más versátiles entre los siglos XVII y XVIII. El primer registro es la ensalada de "El jubilate" de Mateo Flecha del siglo XVI. Asimismo es notoria su pervivencia y difusión por toda España y Latinoamérica incluso como juego infantil. En este artículo se estudia de qué manera la jeringonza se combina en México con un son virreinal llamado "Los panaderos" perseguido por la Inquisición por su contenido blasfemo y erótico; finalmente, se anotan también otras versiones latinoamericanas como juego.

The Jeringonza was one of the most popular dances during $\mathrm{XVII}^{\text {th }}$ and $\mathrm{XVIII}^{\text {th }}$ centuries. It's first version is found in Mateo Flecha's ensalada "El Jubilate" ( $\mathrm{XVI}^{\text {th }}$ century). The Jeringonza's popularity is preserved nowadays in all Spanish spoken communities as a dance and as a girl's game. In this paper I shall study how in Mexico the jeringonza dance was contaminated by "Los panaderos", an old son of colonial times, persecuted by the Inquisition because of it's erotic and blasphemous contents. There are as well versions of it as a children's game in differents parts of Latinoamerica. 
Acta Poetica 26 (1-2)

PRIMAVERA-OTOÑO

2005

Mariana Masera

Instituto de Investigaciones Filológicas, UNAM

\section{Un baile perseguido del siglo xvIII, un son y un juego infantil del xx: algunos textos de la jeringonza en México}

Una de las características de la poesía tradicional es que vive en variantes. Una vez aceptada una versión por los usuarios pasa al acervo colectivo, donde se conserva por medio de la transmisión oral, principalmente, de generación en generación a través de los siglos (Menéndez Pidal 1954). ${ }^{1}$ De hecho la creación y recreación de poemas se realiza dentro de una tradición poético musical específica compartida por la colectividad:

un caudal limitado de tipos melódicos y rítmicos, de temas y motivos literarios de recursos métricos y procedimientos esti-

\footnotetext{
${ }^{1}$ Asimismo conviene repasar las acertadas acepciones que dio José Manuel Pedrosa sobre los diferentes tipos de cancionero donde 1) Cancionero tradicional: es el absolutamente folclorizado, anónimo y "vivo en variantes"; 2) Cancionero oral: englobaría al tradicional, pero también a otro tipo de cancionero más culto, escasamente variable, de autor conocido y transmisión oral sólo subsidiaria y dependiente de modelos escritos; 3) Cancionero popular: englobaría al tradicional y a cualquier otra forma poética cantada (culta o no, de autor conocido o no, no épico-romancística, que llegase a adquirir algún tipo de difusión, de aceptación o de proyección, tanto en el nivel de la interpretación como en el de la recepción, entre el pueblo (Pedrosa 2002, 1067). En mi opinión, y siguiendo a Margit Frenk (2003, 2, n. 1), considero equivalentes los términos "popular y tradicional".
} 
lísticos (caudal limitado, pero no necesariamente reducido). Dentro de él debe moverse el autor de cada nueva canción para que esta pueda divulgarse; dentro de él, también los innumerables individuos que, con el correr del tiempo, la retocan y transforman. (Frenk 1971, 11)

La versatilidad de los textos es explícita, ya que la misma canción puede adaptarse en diferentes regiones para diversas funciones y como consecuencia tiene también nombres distintos, aunque preserve el mismo núcleo textual. Dicho de otra manera, y con la terminología de Sergio Baldi (1946), las variaciones realizadas en cada región serían producto de las diferentes escuelas poéticas populares.

La variabilidad es mayor en los cantares líricos — canciones no-narrativas de breve extensión - pues también afecta a la métrica; es decir, una misma canción puede tener versiones por ejemplo en cuartetas y sextillas octosilábicas o en seguidillas, según la preferencia regional.

Un ejemplo paradigmático de la variación del Cancionero es el texto conocido como la jeringonza que forma parte del repertorio panhispánico. Su primera versión registrada se remonta al siglo XVI, en una ensalada de Mateo Flecha, y perdura hasta nuestros días como baile y como juego infantil en casi toda Hispanoamérica y la Península Ibérica (cf. Gil 1958, Torner 1966, González Ortega 1995). ${ }^{2}$

En este artículo veremos cómo la jeringonza se ha combinado en México con el son de Los panaderos, cuyo primer registro aparece en un proceso de la Inquisición de 1779. El texto antiguo y la versión moderna coinciden en su función, ya que se utilizan para inaugurar los fandangos y como primer son para animar a la gente que salga a bailar. Sin embargo, el cantar moderno ha perdido la sátira religiosa y ha moderado la

\footnotetext{
${ }^{2}$ Los textos de Elfidio Alonso (2001a y b) fueron citados de la página de internet llamada géneros folclóricos por lo cual las citas carecen de numeración.
} 
carga erótica. Los panaderos con su texto moderno también se preserva como juego de velorio de angelito. Asimismo incluimos en este artículo algunas versiones latinoamericanas de la jeringonza como ronda infantil — sin la contaminación del son de los panaderos- de Argentina y Puerto Rico.

\section{Los antecedentes textuales}

Hasta ahora es conocido como el primer testimonio la ensalada de Mateo Flecha (siglo Xvi) llamada El Jubilate, donde la jeringonza podría haber funcionado como un baile para exorcizar a la gente:

Jubilate Deo, omnis terra, cantate et exsultate et psallite ${ }^{3}$

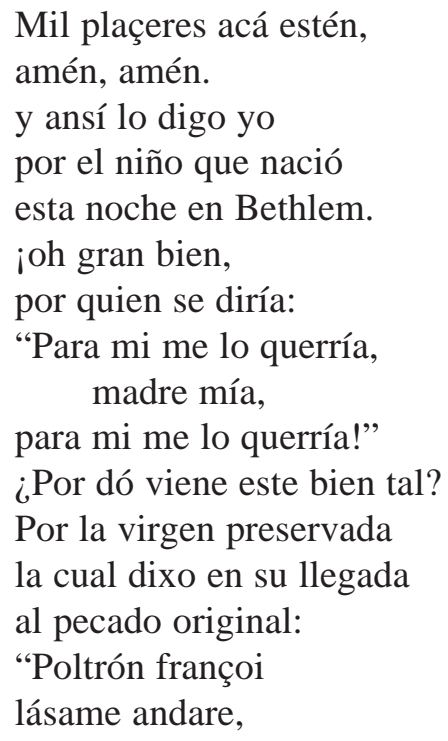

${ }^{3}$ La traducción de los versos en latín son: 'Alegraos en Dios, toda la tierra, / cantad y bailad y salmodiad'. Agradezco la traducción de la maestra Patricia Villaseñor Cuspinera. 
que soy infantina

del bel maridare."

El diablo que la oyó,

se temió,

porque no pudo creer

que lo que la mujer perdió

lo cobremos por mujer.

"¿Que sí puede ser,

señor bachiller!"

"¡Oh qué bonica canción!"

"Mejor le fuera mal año

al tacaño,

y aún quantos con él son,

de la ro-ro-ro-ro-son

que es un vellaco ladrón",

de la ro-ro-ro-ro-son.

En la ciudad de la Gloria

do los serafines son,

en medio de todos ellos

de la ro-ro-ro-ro-son,

cayó un picaro baylón.

El banastón me espanta,

que traga con su garganta

los padres primeros.

¡Oh grosseros!

¿no véys que la Virgen Santa

dixo contra Lucifer:

"Non fay, el cavaller,

non fay tal villanía,

que fillola me soy

de Dios de Abraham,

Señor de la jerarchía.

¡L'anima mía!?”

El maldito replicó.

_ ¡Nunca más paporreó!

Assí, cuerpo de nos!

aquí veré yo 


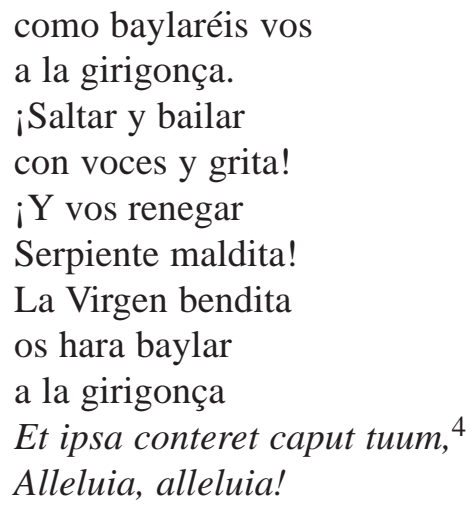

(Anglés 1954, 44-45)

La anterior ensalada - como otras del género- se caracteriza por "la forma 'abierta', que procede por asociaciones más que por un plan riguroso; "la abundancia de diálogos, el estilo coloquial y desenfadado, de alegría carnavalesca" (Frenk 1989, 80). Además de la combinación de cantares de diversas lenguas, existe otra supervivencia antigua registrada en el Nuevo corpus de la antigua lírica donde la jeringonza se asocia con un baile muy difundido denominado la Zarabanda:

El baile de la Jeringonza ¡andar, andola!

El baile de la Zarabanda ¡cómo lo bulle, cómo lo baila!

(NC 1529 ter)

Margit Frenk también señala correspondencias con el teatro de Calderón de la Barca en el entremés de La plazuela de Santa Cruz:

\footnotetext{
${ }^{4}$ La traducción es: 'Ella pisará tu cabeza / Aleluya, aleluya'.

5 La versión que toma Torner (1966, núm. 195) pertenece a la impresión hecha por Fuenllana en su libro para vihuela titulado Orphenyca Lyra (1554): [“'Ansí, ansí, cuerpo de nos!]: Aquí veré yo cómo bayalareis vos / A la Giringoca: / ¡saltar y baylar / con boses y grita! / ¡Y vos renyegar, / serpiente maldita! / La Virgen María / os hará baylar / a la Giringonça”.
} 
Dale, dale, que dale, que dale, que si el aire lo quiso,

[que] páguelo el aire corriendo, volando por el aire.

(apud $\mathrm{NC} 15 \S$ bis $)^{6}$

Elfidio Alonso recuerda que Pérez Vidal propone como origen del nombre jeringonza un romance anónimo de 1598 tomado del manuscrito 19.387 de la Biblioteca Nacional, contra la sátira de Rosas de Oquendo (Perú). La parte que alude a la jeringonza dice así: "Porque si mis pensamientos / su vuelo altivo no abaten / han de ser pueblos de Francia / o xerigonzes lenguaje" (Alonso 2001a).

El término gerigonza está registrado en el siglo XVII por Sebastián de Covarrubias en su Tesoro de la lengua castellana o española, quien además de definir el vocablo ofrece unas etimologías poco fiables:

Un cierto lenguaje particular de que usan los ciegos con que se entienden entre sí. Lo mesmo tienen los gitanos, y también forman lengua los rufianes y los ladrones, que llaman germanía. Dixose gerigonça, quasi gregigionça: porque en tiempos passados era tan peregrina la lengua griega, que aun pocos de los que profesaban facultades la entendían, y assí dezían hablar en griego el que no se dexava entender. $\mathrm{O}$ se dixo del nombre $g y$ rus, gyri, que es buelta y rodeo, por rodear las palabras permutando las sílavas o trastocando las razones; o está corrompido de gytonza lenguaje de gitanos. (1611, sv. jeringonza)

El vocablo “jeringonza”, actualmente, tiene las mismas acepciones de Covarrubias, como se observa en el Diccionario de la Real Academia:

6 Además la estudiosa señala una amplia bibliografía sobre el tema en la sección CORRESPONDENCIAS y en aquella dedicada a los estudios monográficos sobre esta canción. 
Lenguaje especial de algunos gremios, jerga; 2) fam. Lenguaje de malgusto complicado, y difícil de entender, 3) [...] Acción extraña y ridícula. (DRAE 1992, sv. jeringonza)

Los posibles orígenes del vocablo jeringonza también fueron comentados por el folclorista canario Elfidio Alonso, entre otros, quien le dedicó a este baile varios artículos en su columna “Ten-Ten", en el diario La Opinión de Tenerife en 2001. En uno de ellos comenta que

A lo largo de los años - y tal vez de los siglos-, la jeringonza sufrió innumerables transformaciones, no sólo en lo referente a su nombre [...] sino también en relación con su funcionalidad como baile cantado. Del contenido religioso que seguramente engendró el entretenimiento infantil, este género pasaría más tarde a convertirse en un vehículo contestatario en manos de los bajos fondos y del populacho, como así parece indicar el sentido etimológico que nos ofrece Corominas sobre tal nombre: jeringonza de jerga. En 1335 significaría "tela gruesa y tosca", del latín serica (paño de seda). Y en 1734 viene a ser todo lenguaje difícil de comprender, del francés antiguo jargón (gorjeo de los pájaros). De ahí su aplicación a toda habla incomprensible. (Alonso, 2001a)

En tanto que otros autores como Bonifacio Gil (1958, 129130) y Torner $(1966,339)$ han señalado cómo modernamente existe una diversidad de nombres para este baile, según la región a la que se refiera, por ejemplo: en Cataluña se llama Caringosa, Cariñosa o Carrigosa; en Cáceres se le denomina Ciringoncia, en Sevilla Gerigonza, y lo mismo en Granada y León pero con jota. Geringosa en Asturias, Salamanca, Teruel, Logroño y Cáceres, Jerigoncia en Toledo, Jeringonza en Ciudad Real, Nurcia y Cáceres, Jeringoza en Cádiz, Jiringocia Badajoz, Laranza en Toledo y Peringosa en Burgos. Asimismo se le conoce con nombres tan distintos como Tem- 
perendengue en Asturias y en Burgos como Trepeltré. En tanto que en Canarias se asocia en el siglo XVIII con la tonada del Fraile, de acuerdo con Manuel González Ortega (1995, 48-49), hoy se le conoce como La tonadilla del fraile, Danza del fraile o El fraile cornudo. Mientras que en la isla de El Hierro aún se conserva el denominado baile de El flaire $y$ como una variante de La violeta. Además en otras regiones de Canarias se conoce como el sorondongo. En México se le conoce como baile con el título de Los panaderos y como el son solito. ${ }^{7}$

La jeringonza como juego infantil también tiene diversos nombres que se refieren a la invitación al baile o al personaje que realiza el baile, tanto en Latinoamérica como en España, por ejemplo, Qué salga la dama y La señorita en Argentina; Entrando al baile en Puerto Rico; La que ha entrado en el baile en España.

Como hemos visto en los anteriores ejemplos, la jeringonza muestra la facilidad de hibridación tanto en el nombre como en su asociación a diferentes rituales. De acuerdo con Eduardo M. Torner la versión del siglo XVI podría servir para exorcizar:

Esta girigonza bien pudo haber sido una ceremonia celebrada ante la virgen para purificar a los poseídos del demonio, es decir, para "Sacar los demonios del cuerpo", como hoy dice el pueblo, aplicando para ello otros remedios. Por eso en la versión antigua reniega la "serpiente maldita", a la cual obliga la Virgen a huir del cuerpo en medio de las "voces y grita" de los bailadores. (Torner 1969, núm. 195)

Actualmente, en España se encuentra asociado con diferentes rituales en distintas regiones por ejemplo: en Ávila se baila en las fiestas patronales, en Teruel en las fiestas de barrio, en Asturias en las diversiones públicas, en las veladas familiares

\footnotetext{
7 Véase además otros ejemplos de este baile en Cejador y Frauca 1987, 9,
} 4360; González Ortega 1995 y Pedrosa 1994. 
en Burgos y León, en las bodas en Murcia y Toledo, en las faenas de la vendimia en Ciudad Real, en Navidad en Sevilla, y en carnaval en Ávila y Cáceres. En tanto que en otros lugares se ha relacionado con la matanza del cerdo:

si bien la funcionalidad del baile cantado se presenta muy diversa y variopinta, desde su implantación en faenas agrícolas como la vendimia (típica en las zonas vinícolas de La Mancha, como Tomelloso, Valdepeñas y Alcázar de San Juan), hasta la costumbre de convertirse en rito durante las matazones de cochino. (Alonso 2001a) ${ }^{8}$

\section{Además añade Elfidio Alonso que}

Se considera que la vertiente del juego infantil es la más antigua tanto en España como Latinoamérica. Y a partir del siglo XVII el título de jeringoza pierde arraigo y se tiende hacia la tonada del fraile desde el siglo XVIII. (Alonso 2001a)

De acuerdo con los estudiosos del género la versión más antigua de la jeringonza sería la del cancionero infantil:

Parece claro que la jeringonza llegó a Canarias como parte del cancionero infantil antiguo, compuesto por más de cien melodías a una sola voz, que representan arrullos o nanas, rondas, romances, villancicos y demás juegos y entretenimientos, que hoy siguen perdurando bajo distintas formas y nombres

\footnotetext{
${ }^{8}$ La gran difusión del baile de la jeringonza la comprueba una versión bosnia que cantan los Juedo sefarditas durante las bodas. De acuerdo con Silvia Hamui Sutton: "los familiares bailan haciendo un círculo y la novia invita a bailar a su suegra en el centro. Después, la suegra hace lo mismo con otro miembro de la familia hasta que, uno a uno, todos pasan a bailar. Yo kon la mi kusuegra, yo sto kontente / Ke salga a baylar, ke la kero ver // Yo kon la mi kusuegra, yo sto kontente / Ke salga a baylar, ke la kero ver // Yo kon el mi kusuegro, yo sto kontente / Ke salga a baylar, ke lo kero ver // Yo kon los mi kusuergos, yo sto kontente / Ke salgan a baylar, ke los kero ver. (Bosnia, Jagoda, 52; apud Silvia Hamui Sutton en su tesis doctoral que realiza en la UNAM titulada "Simbología poética y vision del mundo en los cantos judeo-españoles".
} 
en América Latina, como nos dice el reputado folclorista uruguayo Lauro Ayestarán: "Algunas de ellas como el Mambrú se incorporaron en el siglo XVIII; otras como 'Se va, se va la lancha' en el XIX; pero la mayor parte data de épocas anteriores como 'Yo la quiero ver bailar', que es el baile español de 'La Gerigonza" del siglo Xvi'. (Alonso, 2001b) ${ }^{9}$

Como hemos visto la jeringonza es uno de los bailes más difundidos en todas las regiones de la Península Ibérica. En este estudio sólo mencionaré una versión asturiana dada por Torner:

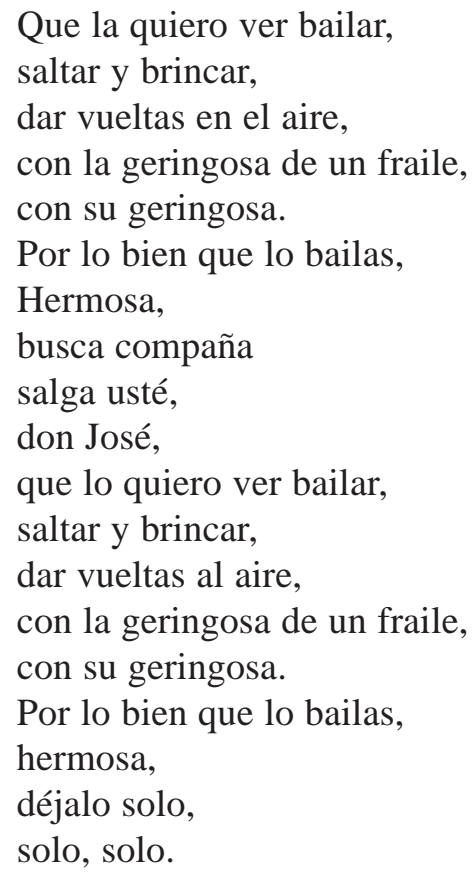

Me interesa añadir aquí algunas versiones canarias llamadas sorondongo "con este nombre se conocía en Canarias a las reu-

${ }^{9}$ Esta opinión contrasta con la del investigador Manuel González Ortega, quien considera la versión de la jeringonza como baile de adultos, la más antigua, basada en los testimonios que hoy poseemos y las opiniones de Eduardo Martínez Torner (cf. González Ortega 1995, 40-41). 
niones que se organizaban en las casas de las parturientas durante las nueve noches que seguían al parto. Los vecinos y familiares velaban el espíritu del recién nacido por temor al demonio y a las brujas. La novena noche se procedía al bautizo del niño" (González Ortega 1992, 2 y 1995, 13) donde se ve claramente la hibridación de la jeringonza con el baile del fraile:

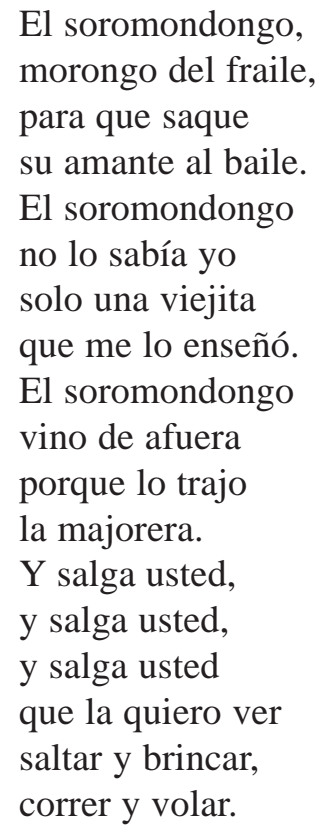

Éste es el baile del fraile que le manda el rey al padre que saque la niña al baile que la quiere ver bailar, saltar y brincar, volar por el aire que la deje sola y que se largue

(González Ortega 1995, El Hierro, 1, 35)

Otra versión de sorondongo la anota Maximiano Trapero en su libro sobre lírica canaria: 


$$
\begin{aligned}
& \text { El sorondongo } \\
& \text { mondongo del fraile, } \\
& \text { que salga la niña, } \\
& \text { que entre y lo baile. }
\end{aligned}
$$

(Trapero 1990, 166)

En tanto que las versiones de la jeringonza como juego infantil, sobre todo de niñas, también se hallan difundidas por todo el cancionero hispánico. Aquí solamente señalo las transcritas por Ana Pelegrín en su libro La flor de la maravilla:

\section{Saltar y brincar}

Salga, usted, salga usted que la quiero ver bailar saltar y brincar dar vueltas al aire.

Esta es la jeringoza del fraile, que bien que lo baila la moza que siga bailando, que la acompañen.

(Pelegrín 1996, Albacete, 51a)

\section{Saltar y brincar}

La señorita

ha entrado en el baile

que lo baile, que lo baile, si no lo baila que lo pague.

Que salga usted

que la quiero ver bailar saltar y brincar dar vuelta al aire, con lo bien que lo baila la moza déjenla sola, sola en el baile.

(Pelegrín 1996, Santander, 51b) 


\title{
Salga la dama, dama
}

\author{
Río Verde, río Verde, \\ río de tantos amores, \\ tanto como el río tiene, \\ así son los mis amores. \\ Que salga la dama, \\ la dama a bailar, \\ dámela, dámela, \\ dámela ya, \\ que salga la damá.
}

(Pelegrín 1996, Santander, 52)

2. Los panaderos un baile perseguido por la inquisición novohispana

La jeringonza en México se combina sobre todo con un son llamado Los panaderos que fue perseguido por la Inquisición novohispana dado su contenido blasfemo erótico en el siglo XVIII. Este baile forma parte de un conjunto de danzas — 41 de acuerdo con Robles Cahero $(1984,30)$ - que fueron condenadas reiteradamente a lo largo del siglo XVII.

Los bailes se ejecutaron principalmente en las ciudades de México, el Bajío, Pachuca, Acapulco y Veracruz. Y las castas que bailaban variaban de acuerdo a las zonas donde se realizaba el baile. En las costas, principalmente fueron los negros y los mulatos; en las zonas mineras fueron los mulatos y los mestizos; en tanto que los criollos y las demás castas e indios los bailaron principalmente en las zonas centrales (cf. Robles Cahero 1984, 30). Asimismo este baile comparte con los demás el contenido de sátira religiosa (por ejemplo el conocido chuchumbé). De hecho casi todos los bailes que llegaron a América regresaron cambiados, como ha comentado Alejo Carpentier: 
las primitivas danzas, traídas de la Península, adquirían una nueva fisonomía en América al ponerse en contacto con el negro y el mestizo. Modificadas en el tempo, en los movimientos; enriquecidas por los gestos y figuras de origen africano, solían hacer el viaje inverso, regresando al punto de partida con caracteres de novedad. (Carpentier 1946, 50-51)

El son de Los panaderos ${ }^{10}$ fue por primera vez denunciado por el fraile Francisco Eligio Sánchez, predicador del Colegio de la Concepción Purísima de María de Celaya en 1779. El fraile envió una carta a los inquisidores pidiendo ayuda para detener la propagación del baile:

Que desprecia los principios de Redempsion, los medios de Nuestra Intercession, y si llama como a terminos del gozo y, del delirio [todo] quanto encuentra de religiosidad. (AGN, Inquisición, 1178, fol. 24r)

En el proceso se anexa un papel de tamaño de un octavo, escrito por ambos lados, con una caligrafía pulcra, donde se describe minuciosamente las coplas y formas de ejecución por los danzantes del baile. Si no estuviera en el proceso, la pulcritud de la letra y la descripción harían pensar más bien que esta hoja servía para la propagación del baile. En el papel se escribió lo siguiente: ${ }^{11}$

Sale una mujer cantando y baylando desembueltamente con estas coplas:

$$
\begin{aligned}
& \text { Esta si q[ue] es Panadera } \\
& \text { que no se sabe chiquear, } \\
& \text { que salga su compañero } \\
& \text { y la venga a acompañar. }
\end{aligned}
$$

\footnotetext{
${ }^{10}$ Recordemos que tanto el pan como los panaderos y, sobre todo, la panadera desde el cancionero medieval han tenido connotaciones eróticas. Sobre todo a la mujer con este oficio se la considera lasciva y lujuriosa. Para una bibliografía más amplia veáse mi estudio sobre este tema Masera 1999.

${ }^{11}$ Esta carta ha sido transcrita tanto por José Antonio Robles Cahero (1984, 34) como por Georges Baudot y María Águeda Méndez (1997, 51-52).
} 
Sale un hombre vaylando y canta [ndo]:

Estos dos siguen baylando con todos los que fueren saliendo.

Salen otro hombre y muger y canta la muger.

Canta el hombre

siguen baylando los 4 :

Salen otros dos hembra y macho.

Canta la hembra

(que no lo hiziera una bestia

y si los judios):

Canta el macho (que sólo los hereges)

Salen otros dos como ha dicho, y siguiendo el mismo son, canto y estribillo
Este sí que es panadero que no se sabe chiquear, y si usted le da un besito comenzara a trabajar.

Esta si que es panadera que no se sabe chiquear quitese usted los calzones $\mathrm{q}[\mathrm{ue}] \mathrm{me}$ quiero festejar.

Este si que es panadero que no se sabe chiquear, lebante usted mas las faldas $\mathrm{q}$ [ue] me quiero festejar Siguen bayilando los cuatro.

Esta si que es panadera que no se sabe chiquear haga usted un crucifixo que me quiero festejar.

Este sí que es panadero que no se sabe chiquear haga usted una dolorosa que me quiero festejar.

Mezclando con la Soledad de Nuestra Señora y otros Santos, perros, guajolotes, lagartijas, pero ban saliendo quantos concurren a el fandango, pero acompañado siempre hombre y muger, y quedandose en el puesto que les toca, baylan y cantan, formando al fin porterías de monjas, Baratillos, fandangos $\mathrm{y}$ todo comercio y comunicacion de 
hombres, y mugeres hasta q[ue] no queda grande ni chico, y quanta mezcla hay sea la q[ue] fuere que no salga a hazer algo. (AGN, Inquisición 1178, fol. 25r-v)

De acuerdo con la carta, la culpable de haber propagado el baile fue "un demonio (que ya se fue) en forma de muger q[ue bino de Bayadolid".

La relación entre la música popular antigua y los sones que hoy se cantan también ha sido motivo de diversos estudiosos de la música. Humberto Aguirre Tinoco (1983, 12-13) comenta que el vocablo Son sirve para designar al baile y al canto desde el siglo XVIII, ya que antes son se utilizaba exclusivamente para designar a la música.

Las raíces peninsulares del son a pesar de ser un género netamente mestizo también constituyen un hecho aceptado por los especialistas en el tema:

relativo a los orígenes del son, la mayoría de los autores que han profundizado en el tema confluyen en la opinión que éste, así como el resto de la música mestiza tradicional mexicana, se configura a partir de la música tradicional española, que los conquistadores trajeron consigo e introdujeron en la nueva tierra. Los géneros implicados pertenecen muy posiblemente a las provincias de Andalucía, Extremadura, Murcia y Castilla. (Llerenas, Ramírez de Arellano, Lieberman, 1985) ${ }^{12}$

El son de Los panaderos hoy tiene gran difusión en varias regiones de México donde también se le conoce como $\mathrm{El}$ son solito. De acuerdo con Rosa Virginia Sánchez (en prensa): ${ }^{13}$

\footnotetext{
12 Véanse además los trabajos de Reuter (1992) y Heredia Vázquez (2004).

13 Debo agradecer a Rosa Virginia Sánchez los materiales en prensa, además quiero señalar que este artículo forma parte de una investigación que estamos realizando en conjunto, donde los textos de la jeringonza se acompañarán con sus melodías.
} 
A pesar de la diferencia de los títulos, el parecido que guardan las coplas de las diversas variantes regionales, así como su función coreográfica característica - la de provocar que todos los presentes salgan a bailar-, delatan su parentesco. Para muestra basta un botón: compárese la siguiente cuarteta de nuestro Son solito con otra que se canta en Los panaderos de Tierra Caliente de Michoacán

Dispénseme, caballero

dispense, que voy a hablar:

que busque su compañera

que lo acompañe a bailar.

(Huasteca. Trío sin nombre)

Qué bonito panadero

me ha salido aquí a bailar;

que busque a su compañera

que le ayude a amasar pan.

(Tumbiscatío, Michoacán. Los Alegres de Michoacán)

La musicóloga hace notar en su estudio la variedad métrica de los sones según la región de que se trate, además señala la mayor antigüedad de aquellos sones que tienen como recurso principal el paralelismo. Aquí añadiremos a los anteriores ejemplos las dos versiones completas de este baile que están registradas en el Cancionero Folklórico de México. La primera proviene de San Mateo Etlongo de Oaxaca y se ha denominado como Los panaderos I y la segunda versión denominada, Los panaderos II, proviene de Veracruz. En ellos prevalece la sextilla.

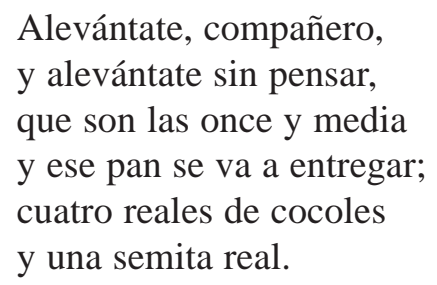


¿Qué bonito compañero!, y ha salido ya a bailar; se parece a un panadero y acabado de llegar; cuatro reales de cocoles y una semita real.

(Frenk 1975-1985, 4, 296)

¡Arriba los panaderos, arriba, arriba y a trabajar!; que busque su compañera quien la tiene que encontrar; que la busque, que la busque, que ahora me la va a pagar, y si no quiere salir, que la chiflarán, que la chiflarán.

Bonita compañerita se ha venido usted a encontrar; déjemela usted solita, que la voy a hacer bailar, que me baile "El ahualulco"14 ¡a ver si sabe bailar!

¡Arriba los panaderos, arriba, arriba y a trabajar!; que busque su compañero, que lo tiene que encontrar;

14 Este son muy antiguo se asocia al son del Aguanieve que se canta en Veracruz ha sido estudiado por Humberto Aguirre Tinoco (1983, 21-26) quien comenta que éste estaría relacionado con la arriería. Además el nombre significa "henchido de agua" y también sirve para designar la marisma. Interesante también es notar aquí que "con el nombre de Los Ahualulcos fue identificada, en la época colonial, la región del hoy estado de Tabasco cubierta de marismas, que se hallan en torno de la Laguna de Términos. Era célebre entonces por estar en posesión de los filibusteros, que aprovechaban el resguardo de sus esteros y ensenadas para, desde allí, salir al ataque de los demás puertos del Golfo de México como Veracruz, Campeche, Alvarado, etc., y mantener el saqueo de las flotas españolas" $(1983,23)$. 
que lo busque, que lo busque, que lo tiene que encontrar.

\section{Bonito compañerito \\ se ha venido usted a topar; parece un pichoncito sacado del palomar; déjemelo usted solito, ¡a ver si sabe bailar! que baile una "Bambita"15 ¡ a ver si sabe bailar!}

¡Arriba los panaderos arriba, arriba y a trabajar!; que busque su compañero, que lo tiene que encontrar; que lo busque, que lo busque, que lo tiene que encontrar.

\section{Bonita compañerita}

se ha venido usted a encontrar; y si no quiere salir, que le chiflarán, que le chiflarán; que le baile un "Ahualulco", ¡a ver si sabe bailar!

¡Arriba los panaderos, y arriba, arriba y a trabajar! ¡qué buenos bracitos tiene, qué buen pan ha de amasar! Déjemelo usted solito, que ahora me la va a pagar; que se busque compañera, que la quiero ver bailar.

${ }^{15}$ Aquí se refiere a el baile de La Bamba (Frenk 1975-1985, 5, 14). 


\begin{abstract}
Déjemela usted solita que ahora me la va a pagar; y si no quiere salir, le chiflarán, que le chiflarán; que le toquen "El Colás", 16 que la quiero ver bailar.
\end{abstract}

(Frenk 1975-1985, 4, 297)

El son de Los panaderos en Tlacotalpan (Veracruz) se utiliza como castigo. Una vez que se ha reunido suficiente gente alrededor de la tarima para realizar la fiesta, los músicos ejecutan este son para hacer bailar a alguien que haga el ridículo. De ahí que se considere como un castigo impuesto al improvisado bailador (cf. Aguirre Tinoco 1983, 99-100): Aguirre Tinoco registra la siguiente versión:

-estribillo-

\title{
Arriba arriba \\ los panaderos \\ arriba arriba \\ y a amasar el pan.
}

Busque usted su compañera que le ayude a trabajar. Que la busque y que la busque que la busque y la ha de bailar

y si no quiere salir que le chiflarán que le chiflarán.

Qué bonita compañerita ha venido usted a encontrar se parece a una azucena acabada de cortar.

16 Véase en Frenk 1975-1985 (5, 33) una versión del baile denominado El Colás. 
Déjemela usted solita que ahora me las va a pagar que le toquen un zapateado que lo habrá de zapatear. (entra el zapateado)

Que bonito zapateado ella acaba de bailar arriba arriba los panaderos arriba arriba y a amasar el pan.

Busque usted su compañerito que le ayude a trabajar y si no quiere salir que le chiflarán que le chiflarán.

Que bonito compañerito acaba usted de encontrar que parece un zopilote acabado de mojar.

Déjemelo usted solito que ahora me las va a pagar que baile los enanitos a ver si sabe bailar (Entra este son u otro y continúan por el mismo estilo).

(Aguirre Tinoco 1983, 100)

De acuerdo con lo visto se sabe que cada región le da ciertos rasgos diferentes al baile. Por ejemplo en Michoacán según un testimonio recogido por María Storm:

Para romper el hielo en una fiesta concurrida, siempre pedimos a los músicos que toquen "Los panaderos". Todos disfrutamos de esta vieja ronda familiar, como niños, tal como lo hacemos [en Estados Unidos] con "Virginia Reel"; pero cansa 
a los músicos y por ellos no hacen caso a una segunda o tercera petición.

"Los panaderos" es muy divertido. Todos en rueda tararean "iQué bonito panadero que ha salido a bailar!" y uno de la fila se coloca en medio. El como es sabido, busca "una bonita panadera" que le ayude a hacer el pan, sonriendo le saca de la rueda y bailan juntos un ratito. Después ella baila sola y busca a otro compañero que le ayude a trabajar; por supuesto que uno nunca sabe a quien se escogerá, y así sigue. Muy bonito. (Storm 1992, 122-123)

Añado también una versión que recogí de don Martín Villano, conocido músico y decimero de Tierra Caliente de Michoacán - gracias a la intervención de Raúl Eduardo González-, quien comentó que el son de Los panaderos se utiliza para inaugurar el fandango y que después de cantarlo se toca un jarabe.

¡Qué bonitos panaderos

me salieron a bailar!

Que me la dejen solita

para mirarla bailar.

Panadera, panadera, te miro muy decedida [sic]

se me hace que tú me cantas

el son de "La aparecida".

Canta, canta, compañera, no te dé tanta vergüenza, si algo se te dificulta, aquí 'toy en tu defensa. [sic]

¡Qué bonita panadera

la que salió aquí a bailar!

Que busque a su compañero que le ayude a zapatear.

(Martín Villano, octubre 2005) 


\title{
3. Los panaderos como juego infantil
}

En algunas comunidades de Tlaxcala, como Totolac y Tenate, Los panaderos se canta como juego durante el velorio de un niño (conocido como velorios de "angelito"). Se conserva en las estrofas las rimas en ar. El juego consta de dos personas que bailan al centro mientras los otros del corro le hacen indicaciones sobre cómo deben bailar o las actividades a realizar. Veamos la primera versión de Totolac como la describe Lillian Schefler:

Dos jugadores, un hombre y una mujer, pasan al centro, los demás forman un círculo, parados a su alrededor y cantan:
Arriménse otro poquito
que los quiero ver gustar, y éstos sí son panaderos que no saben chiquiar.

Los del centro deben ir haciendo lo que los del círculo les indican:

\author{
Háganse una rosquillita \\ que los quiero ver gustar... \\ Háganse una risita... \\ Dense una espulgadita
}

Todo lo que se les va ocurriendo, al terminar les cantan:

Arriba mis panaderos

que acaban de trabajar.

En ese momento los que estaban sentados en el centro pasan al círculo y escogen a otros dos que ocupan el lugar central, para volver a comenzar el juego (Schefler, 1976, 72-73). 
La investigadora comenta que el juego se acompañaba con instrumentos musicales como violines y contrabajo en épocas anteriores, pero actualmente sólo se canta (cf. Schefler, 1976, 73). ${ }^{17}$ Otro investigador afirma, aunque no comparto su opinión, que este juego podría haber sido introducido a principios de siglo xx y que está relacionado con la principal labor del pueblo que es el pan (Sevilla Villalobos et al., 1983, 211).

En cambio, en la comunidad de Tenate, una comunidad bastante aislada y preservadora de una gran variedad de juegos infantiles, se añaden más estrofas y el juego es más complejo. En esta versión la invitación al baile típica de La jeringonza se hace explícita:
Salga usted doña Ana Andrea, salga usted de su zalea, qué bonita panadera tiene cuerpo de ballena.
Ciérnele, ciérnele, panadera por delante y por detrás, que ya son las once y media y ese pan se ha de entregar, cuatro reales de cocoles y una semita de a real.

Luego le dicen cantando que escoja a su compañero para que le ayude a trabajar, ella le pone el sombrero a uno de los niños o jóvenes y ése pasa al centro con ella, mientras las demás cantan:

Salga usted Tata Simón, salga usted de su rincón,

\footnotetext{
${ }^{17}$ Otra versión de Los panaderitos fue anotada por Arturo Chamorro en la que los primeros dos versos de las primeras estrofas no se transcriben y continúa "cuatro reales de cocol / y una semita de real // Ora sí mi panadero, / te he venido yo a sacar, / que te busques tu compañera / que te ayude a hacer el pan. // Ora sí , mi compañero, / yo te vengo yo a mandar / que te busques compañera, / que te ayude a hacer el pan" $(1983,46)$.
} 
qué bonito panadero

tiene cuerpo de barril.

Ciérnele, ciérnele, panadero

por delante y por detrás (etc.).

En seguida se detienen y los demás les indican cantando lo que deben ir haciendo:

Escuche usted panadero

lo que van a hacer.

Siéntense un ratito

un ratito a descansar.

Ambos se sientan en medio del círculo, todos cantan:

Búsquense un piojito

(hace como que se lo buscan uno a otro)

Háganse un celito [y los bailadores cantan]

él: ¿En dónde estabas?

ella: Con otro.

El muchacho se enoja cuando ella le dice que "con otro", se levanta y dan vueltas otra vez, y los otros jugadores le indican que regrese a su lugar:

Salga usted panadera

vuelva usted a su lugar.

El joven se queda en medio y todos cantan otra vez [el estribillo]:

Ciérnele, ciérnele, panadero

por delante y por detrás etc.

Nuevamente cantando le dicen que escoja a su compañera. 
Éste escoge a otra jugadora poniéndole el sombrero, cuando pasa al centro, cantan:

$$
\begin{aligned}
& \text { Salga usted Doña Andrea } \\
& \text { salga usted de su zalea } \\
& \text { qué bonita panadera } \\
& \text { tiene cuerpo de garrote. }
\end{aligned}
$$

Luego otra vez:

Ciérnele, ciérnele panadero (etc.)

Y se repite en forma idéntica

(Schefler, 1976, 80-82)

La conservación de este baile en el cancionero contemporáneo nos puede ayudar a comprender mejor el texto censurado por la Inquisición en el siglo XVIII, del cual sólo quedan algunas estrofas aisladas. Asimismo la forma similar de estructurar la danza o el juego actualmente permite reconstruir la ejecución de la danza virreinal. En tanto que la letra y el modo de realización del juego de Tlaxcala sugieren una estrecha relación con el baile novohispano y la jeringonza peninsular. Además aquí habría que agregar que la última estrofa de este juego se asocia con otro son, que fue recopilado desde el siglo XIX, llamado Los enanos (que a veces se toca después del son de los panaderos vid supra), donde los danzantes "de acuerdo con Miguel Ríos Toledano se hacen 'chiquitos y grandotes al compás del son"” (1884 apud Juan José Escorza 1992, 21). La estrofa a la que me refiero es

$$
\begin{aligned}
& \text { Sale la linda, } \\
& \text { sale la fea, } \\
& \text { sale la enana } \\
& \text { con su zalea. }{ }^{18}
\end{aligned}
$$

\footnotetext{
${ }^{18}$ La zalea, de acuerdo con Covarrubias (1998), es "la piel de esquilar, que está con su lana o bellón. Estas se usan en Valencia y en otras partes, para poner a
} 
Por último, agrego en esta sección otro ejemplo mexicano del son, cuya letra no muestra una relación directa con el son de Los panaderos. Pertenece al cancionero infantil del Distrito Federal. La informante comenta que la cantaban para amenizar los viajes y es similar a la versión del cancionero infantil el recopilado por Mercedes Díaz Roig y María Teresa Miaja (1993):

\author{
La comadre Juana \\ andaba en un baile \\ que lo baile, que lo baile, \\ y si no lo baila \\ le doy cuartilla de agua. \\ Que salga usted \\ que la quiero ver bailar \\ cantar y gozar \\ con las patas al aire. \\ Por lo bien que lo baila la moza \\ déjenla sola sola en el baile \\ que la quiero ver bailar.
}

(Josefina Flores, 10 de octubre de 2005) ${ }^{19}$

Esta versión se parece a una ronda infantil donde se menciona a la "Señorita Juana" y que ha sido registrada en varios lugares tanto de Badajoz y Extremadura (Gil 1958, 146) como en algunas versiones canarias de Lanzarote (González Ortega 1995). El personaje también aparece en una versión de la

los niños en la cama porque no pudran los colchones, y a algunos viejos que tiene mal de orina" s.v. çalea. Además Santamaría (1992) comenta que se denomina zalea al "Cuero, piel en general" s.v. zalea.

${ }^{19}$ Esta versión se asocia con los juegos infantiles de Canarias. El texto es similar a la del juego denominado La que ha entrado en el baile recogida por Cuscoy y Alonso en 1944 y luego por González Ortega: "La señorita X / que ha entrado en el baile, / que lo baile, que lo baile. // Y si no lo baila / le da un cuartillo de agua, / que lo pague, que lo pague. / Que salga usted, que la quiero ver bailar, / saltar, brincar y andar por los aires, / por lo bien que lo baila la moza, / déjenla sola, sola en el baile" (González Ortega 1995). 
jeringonza de La Mancha que se canta para las fiestas de la Vendimia. La protagonista es "María Juana" en las coplas que por su tono satírico se relacionan más con el tema de las comadres borrachas: ${ }^{20}$

María Juana, / la que giraba, bebía vino y / se emborrachaba;

y a su niño la teta le daba, Comiera tuerta, / con el dedo trancaba la puerta.

(Gil 1958, 141)

De acuerdo con los investigadores Félix y Martha Isabel Coluccio en su interesante obra denominada Diccionario de juegos infantiles latinoamericanos, la jeringonza se registra como un baile infantil que en Argentina se llama La señorita:

es una ronda infantil de origen español, donde ya se la conocía en el siglo XVI. Curiosamente en España su vigencia es total y lo que es más importante, ha pasado a ser ronda que bailan los mayores. Se le conocía con el nombre de la geringoza (Coluccio y Coluccio 1988, 385).

Déjenla sola, solita y sola, que la quiero ver bailar, saltar y brincar, andar por los aires con mucho donaire.

\footnotetext{
${ }^{20}$ No podemos dejar de comentar que el personaje de María Juana también se asocia en México a la mariguana. Y en Mendoza (Argentina) al botellón de vino se le llama Dama Juana: "Mi comadre Juana / andaba en un baile / que lo baile, que lo baile, / y si no lo baila, / le doy castigo de agua // Que salga usted, / que lo quiero ver bailar, / saltando, bailando / las patas al aire // Por lo bien que lo baila la moza,/ déjela sola, sola en un baile, / que la quiero ver bailar" (Díaz Roig 1993).
} 
Debo agregar a las versiones de Coluccio una que canté durante mi infancia en Mendoza, Argentina. Se baila haciendo una ronda donde las niñas palmotean; una de ellas danza al centro y saca a otra a bailar con la estrofa 1. Posteriormente, con la estrofa 2 se señala que se debe dejar a la recién elegida sola. La ronda continúa hasta que se cansen las participantes.

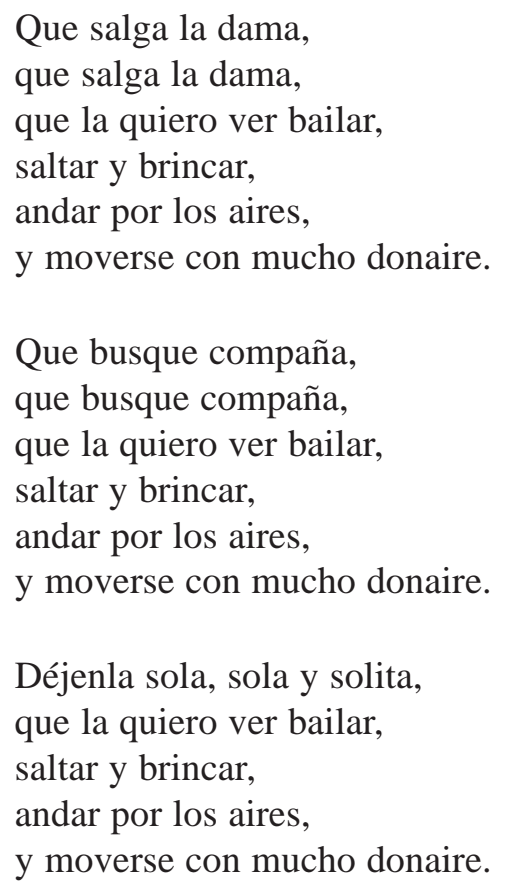

(Mariana Masera, tradición oral)

La versión de Tucumán que transcribe Torner (1969) de la recopilación de Juan Alfonso Carrizo (1937) es la más parecida a la que acabo de anotar:

Que salga Anita, que salga Anita, que la quiero ver bailar, saltar y jugar, 
andar por los aires

sin moverse, con mucho donaire.

Busca compaña,

busca compaña,

que la quiero ver bailar,

saltar y jugar,

andar por los aires

sin moverse, con mucho donaire.

Déjala sola, sola, solita,

Que la quiero ver bailar,

saltar y jugar,

andar por los aires

sin moverse, con mucho donaire.

(Carrizo 1937, I, 105)

Los investigadores Félix y Martha Coluccio señalan este texto como ronda infantil recogida por Miguel Cardona en Venezuela

Una niña en el centro y las demás forman la rueda, palmoteando acompasadamente; todas cantan:

—La señorita Victoria

Que va a entrar al baile

Que la baile

Y si no la baila

Le da un cuartillo malo

que la saque

que la saque.

La que está en el centro dice:

—iSalga usted!

Sola solita.

En este momento coge a una de las niñas y dan vueltas las dos en el centro. 
- Salga usted

que la quiero ver bailar

Venezuela baila la moza

Déjala sola.

En este momento baila en el centro sin agarrarse. Siempre los demás van palmoteando acompasadamente.

(Coluccio y Coluccio 1988, 386-387)

En Puerto Rico, se conoce este juego como Entrando en el baile. Las niñas forman dos hileras, una enfrente de la otra. Una niña se va de un extremo a otro mientras cantan. Y cuando se canta "venga usted conmigo" debe elegir a un niño y se deslizan de un extremo a otro. Luego al decir "déjalo solo" la niña vuelve a la hilera de niñas y el niño debe elegir otra niña. Y se repite. En la nota se explica que se canta la canción con el nombre de la niña que comienza el baile y se substituye el término "señorito" por el nombre del niño. Esta forma de ponerse en hilera es similar en danzas de Canarias y Salamanca.

La señorita Carmen entrando en el baile.

Que lo baile, que lo baile.

Y si no lo baila le daré un castigo malo, pero malo, malo.

Venga usted, que lo quiero ver bailar.

Déjalo solo, solo, solito.

(Pescador de Umpierre 1973, 243)

\section{Conclusión}

Este recorrido por algunas versiones mexicanas de la jeringonza desde el siglo XVIII hasta la actualidad confirma la gran difusión de ésta y su permanencia en la tradición. Desde los primeros registros la jeringonza ha sido de tal modo 
versátil que se mezcla fácilmente con otros bailes como el del fraile, el mondongo, los panaderos, la zarabanda y los enanos. Por otra parte, contrasta la asombrosa estabilidad de los textos en la preservación, casi idéntica, de la invitación al baile, a pesar de sus diferentes funciones (como baile de adultos asociado a ritos agrícolas, a los partos, $\mathrm{y}$, a veces, como corro infantil incluso para velorios de "angelito"). De acuerdo con Sachs se trata de una danza de galanteos propia de los ritmos iniciáticos de fertilidad, cuya característica más curiosa es aquí el continuo cambio de pareja en cadena como si subyaciera en ello una significación tendiente a subrayar la interrelación de los individuos y la consiguiente cohesión de grupo (apud González Ortega 1995, 49). Todo ello podría ser indicativo de su gran arraigo pero aún nos faltan estudios para saber realmente cuáles fueron sus usos. Lo que sí sabemos es que como otros bailes de cosecha algo erótico y satírico, la influencia africana está presente.

El estudio de las versiones de la jeringonza nos permite entrar en el acervo del cancionero panhispánico mostrando cuánto en común poseemos, a pesar de las innumerables variantes que existen. Es decir, una canción puede viajar grandes distancias y echar raíces en las más variadas geografías sin perder su núcleo temático.

La constante hibridación de los textos evade cualquier tipo de prohibición y fomenta la creatividad de quienes los cantan. Como vimos, en México el son de Los panaderos escapó de la censura y se transformó al combinarse con la jeringonza.

Sin embargo, este trabajo también deja claro que todavía hay mucho camino por andar en la recopilación e investigación de la jeringonza de Latinoamérica desde el Virreinato hasta nuestros días, investigación que nos permitirá conocer más a fondo el andamiaje del cancionero tradicional mexicano. 


\section{REFERENCIAS}

Alonso, Elfidio, 2001a. "Los vaivenes de la jeringoza", Ten-Ten, La opinión de Tenerife, 6 de octubre.

—, 2001b. "Supervivencias canarias de la jeringoza", Ten-Ten, La opinión de Tenerife, 3 de noviembre.

Aguirre Tinoco, Humberto, 1983. Sones de la tierra y cantares jarochos, México, Premia Editora, La red de Jonás.

Anglés, Higinio, 1954. Mateo Flecha (1553) Las Ensaladas (Praga 1581), Barcelona, Biblioteca Central.

BALDI, Sergio, 1946. "Sul concetto di poesia popolare", Leonardo. Rassegna Bibliografica (Firenze) 15, 11-21 y 65-77.

BAudot, Georges y María Águeda Méndez, 1997. Amores prohibidos, México, Siglo XXI.

Carpentier, Alejo, 1946. La música en cuba, México, Fondo de Cultura Económica.

Carrizo, Juan Alfonso, 1937. Cancionero popular de Tucumán, 2 tomos, Tucumán, Universidad Nacional de Tucumán.

Catalán, Diego, 1997. Arte poética del romancero oral. Parte $1^{a}$. Los textos abiertos de creación colectiva, Madrid, Siglo XXI.

Cejador y Frauca, Julio, 1987 [1921-1930]. La verdadera poesía castellana. Floresta de la antigua lírica popular, 10 vols, Madrid, Arco Libros.

Chamorro, Arturo, 1983. La música popular en Tlaxcala, México, Premia Editora, La red de Jonás.

Coluccio, Félix y Martha Isabel Coluccio, 1988. Diccionario de juegos infantiles latinoamericanos, Buenos Aires, Corregidor.

Covarrubias, Sebastián de, 1998 [1611]. Tesoro de la lengua castellana o española, Martín de Riquer (ed.), Barcelona, Alta fulla, Adlitteram, 3.

DíAz Roig, Mercedes y María Teresa Miaja (eds.), 1993. Naranja dulce, limón partido. Antología de la lírica infantil mexicana, México, El Colegio de México.

Diccionario de la lengua española, 1992. Madrid, Real Academia Española ( $21^{\mathrm{a}}$ ed.).

EscorZA, Juan José, 1992. "Apuntamientos sobre el jarabe mexicano”, Heterofonía 107, 11-24. 
Frenk, Margit, 1971. Entre folklore y literatura, México, El Colegio de México.

— (ed.), 1989. González de Eslava, Fernán, Villancicos, romances, ensaladas y otras canciones devotas (Libro segundo de los coloquios espirituales y sacramentales y Canciones divinas), Biblioteca Novohispana, I, México, El Colegio de México.

—, 2003. Nuevo corpus de la antigua lírica popular hispánica (siglos XV a XVII), México, UNAM, El Colegio de México, Fondo de Cultura Económica.

-, (coord.), 1975-1985. Cancionero Folklórico de México, 5 vols, México, El Colegio de México.

GIL, Bonifacio, 1958. "La jeringonza en la actual tradición", Аnиario Musical 3, 129-158.

GonzÁlez Ortega, Manuel, 1992. "El Sorondongo, una versión canaria de la jeringonza", Revista de Musicología 15-1, 9-46.

González Ortega, Manuel, 1995. El Sorondongo, Las Palmas, Centro de la Cultura Popular Canaria.

Heredia VázQuez, Rubén, 2004. "El son, esencia musical de México", Correo del Maestro 98 (julio). Tomado de http://www. correodelmaestro.com/anteriores/2004/julio/indice98.htm

Llerenas Eduardo, Enrique Ramírez de Arellano y Baruj LieBERMAN, (Investigación, grabaciones de campo, textos y fotografías) 1985, Antología del Son de México, Música tradicional: tomado de la página web http://www.folklorico.com/musica/antologia-son.html.Folkórico Dance Music

MARTínez TORNer, Eduardo, 1966. Lírica hispánica: relaciones entre lo popular y lo culto, Madrid, Castalia (La lupa y el escalpelo, 5).

Masera, Mariana, 1999. "'Que non sé filar, ni aspar, ni devanar': erotismo y trabajo femenino en el Cancionero Hispánico Medieval", en Discursos y representaciones en la Edad Media, Concepción Company, Aurelio González y Lillian von der Walde Moheno (eds.), México, UNAM, El Colegio de México, pp. 215-231.

MÉnéndez Pidal, Ramón, 1954. Cómo vive un romance, Anejo XL de la Revista de Filología Española, 1-141.

Pedrosa, José Manuel, 1994. "Notas y adendas al Corpus de la antigua lírica popular hispánica (siglos XV a XVII) de M. Frenk (y 
apostillas a dos reseñas de D. Devoto)", Anuario de Letras XXXII, 209-250.

Pedrosa, José Manuel, 2002 ."El cancionero tradicional medieval" en Diccionario Filológico de la Edad Media, Carlos Alvar y José Manuel Lucía Megia (eds.), Madrid, Castalia, pp. 10671073.

Pelegrín, Ana, 1996. La flor de la maravilla: juegos, recreos y retahílas, Madrid, Fundación Germán Sánchez Ruipérez.

Pescador de Umpierre, Paquita, 1973. Manual de bailes Folklóricos, San Juan, Puerto Rico, Editorial universitaria.

Robles Cahero, José Antonio, 1984. "La memoria del cuerpo y la transmisión cultural: las danzas populares en el siglo XVIII novohispano", Heterofonía 2, 26-43.

Reuter, Jas, 1992. La música popular de México, México, Panorama.

SÁnchez García, Rosa Virginia (en prensa). "El paralelismo en los sones de la Huasteca", Revista de Literaturas Populares 5-2.

Sevilla Villalobos, Amparo, Hilda Rodríguez PeÑa, Elizabeth CAmara García, 1983. Danzas y bailes tradicionales del Estado de Tlaxcala, México, Premia Editora, La red de Jonás.

Storm, Maria, 1992."Ecos de sones tarascos. La música de Michoacán", en Álvaro Ochoa, Mitote, fandango y mariacheros, Zamora, El Colegio de Michoacán, pp. 122-123.

Trapero, Maximiano, 1990. La lírica tradicional canaria, La Palma, Islas Canarias (Biblioteca Básica Canaria, 3).

Página web:

http//:www.terra.es/personal/folias55/GenerosFolkloricosdeCanarias/sorondongo/sorondon.htm 